\title{
Effect of Bio-Disc on Distillate Yield and Crude Oil Properties
}

\author{
Anthony Kerunwa, Princewill 0. Ariche \\ Federal university of Technology, Owerri, Nigeria \\ Email: anthonykerunwa@rocketmail.com
}

How to cite this paper: Kerunwa, A. and Ariche, P.O. (2020) Effect of Bio-Disc on Distillate Yield and Crude Oil Properties. World Journal of Engineering and Technology, 8, 367-381.

https://doi.org/10.4236/wjet.2020.83028

Received: May 28, 2020

Accepted: July 26, 2020

Published: July 29, 2020

Copyright $\odot 2020$ by author(s) and Scientific Research Publishing Inc. This work is licensed under the Creative Commons Attribution International License (CC BY 4.0).

http://creativecommons.org/licenses/by/4.0/

\section{(c) (i) Open Access}

\begin{abstract}
The market worth of the crude oil transported to the international market has a great influence on the crude's physical properties, as such demands that certain desirable physical properties ought to be possessed. The distillation of crude oil is the first process in the sequence of refining operation and is key to refinery operations profitability. In this work, five crude oil samples were collected from a reservoir in the Niger Delta designated as S11A, S12A, S13A, S14A and S15A. Sample S11A was not treated with bio-disc while samples S12A-S15A were treated with bio-disc at different number of times. This was necessary to ascertain the effect of the bio-disc on crude oil physical properties and their distillate yield. After the treatment, the specific gravity, American Petroleum Institute (API), pour point, flash point and viscosity of the treated and untreated crude samples were determined and then the samples distilled with a distillation tester. From the results obtained, the bio-disc had a great influence on the physical properties of the samples as well as on the distillate yield. The specific gravities of the oil samples decreased as the number of times the samples were treated with bio-disc increases and this in turn increased the crudes' API. The pourpoint and viscosity decreased with increase in number of treatments of crude samples with bio-disc. As the number of treatments increased, the crude samples which were originally paraffinic were tending towards being naphthenic. The flash point and distillate yield increased with increase in number of treatments of crude samples with bio-disc. Thus, treatment of crude oil with bio-dic alters the physical properties of the crude.
\end{abstract}

\section{Keywords}

Hydrocarbon, Flash Point, Specific Gravity, Refining, Viscosity, Distillation, Petroleum Products

\section{Introduction}

Crude oil usually known as "black gold" is a complex liquid mixture that occurs 
naturally and contains mostly hydrocarbons with other elements like oxygen, nitrogen and sulfur. It is yellowish-black in nature and is found in geological formations underneath the surface of the earth. Its hydrocarbons are of diverse molecular weights. Crude oil (petroleum) is naturally unprocessed and when processed, petroleum products are obtained. Petroleum formation occurs when enormous quantities of buried dead organisms beneath sedimentary rock, majorly algae and zooplankton are subjected to high intensity of heat as well as pressure. It is commonly refined into diverse kinds of fuels. Petroleum is utilized in the manufacture of a great variety of products and world estimation of petroleum consumption stood at $95 \mathrm{mmb} / \mathrm{d}$ [1]. The hydrocarbon compounds in crude oil are majorly paraffins ranging from pentane to pentadecane $\left(C_{5}-C_{15}\right)$, alkyl paraffins, napthenes, alkylbenzenes and nuclear aromatics. Crude oil can thus be said to be paraffin-based, napthene based or mixed based, depending on the most abundant group of hydrocarbon contained. It can be classified as sweet or sour depending on its sulphur content. It is extracted from the earth in liquid state. "Oil drilling" is the key technique for the production of petroleum. Drilling is undertaken when the structural geology of the reservoir, analysis of the sedimentary basin and the characterisation of the reservoir has been ascertained WRT the permeability and porosity geological structures. Crude oil exhibits certain key physical properties which are utilized in analyzing its economic value especially at the international market. Such physical properties include its specific gravity, API, viscosity, pour point and flash point. The specific gravity of crude oil is a measure of its density, API is a measure of its worth to the producer, it measures how light or heavy a crude oil sample is. The viscosity of crude oil measures its internal resistance to flow. The pour point reveals the influence of low temperatures on crude oil and at same time provides information about the paraffin wax content of the crude oil. The flash point of crude oil measures its flammability. These physical properties of crude oil are measured following standard laboratory methods as specified by API and ASTM standards. Majority of the crude oil physical properties such as API gravity, viscosity are dependent on reservoir temperatures and pressures; chemical composition of the crude oil and on the amount of dissolved gases present [2]. Crude oil yields numerous products. The separation of these products is achieved through a technique termed fractional distillation. Crude oil distillation remains the front end of every refinery, regardless of size or overall configuration. Fractional distillation is a straightforward refining process. Fractional distillation involves the separation of the crude oil constituents through the utilization of the differences in their BT [3]. One of the methods used to alter the physical properties of crude oil is by treating it with the bio-disc. Treatment of crude oil with the bio-disc is a phenomenon which involves pouring the crude oil over the concave side of the bio-disc for an effective contact with it. This is because the crude oil when in contact with the bio-disc is being energized thereby influencing its physical properties. The bio-disc is a saucer-like piece of glass embedded under nanotechnology with minerals which emit wave frequencies that maybe transmitted 
to other bodies by means of resonance. The effect is most felt by liquids whose physical properties might be altered. One of such physical properties is viscosity and consistency. These are known to be reduced thereby making the fluid more mobile and easy to flow. The bio-disc is a device that generates energy naturally. The created energy explicitly causes a rejuvenation of the molecular structures present in the liquids. The molecular structure thus causes the liquid to become hydratious. The bio-disc is made up of natural minerals, which are naturally bonded by nano-fusion technology and by heat fusion method; it has thirteen (13) minerals that are technically engineered through nano fusion process by utilizing different heat fusion approaches that bonds the minerals structurally together at the molecular level. The minerals when combined with the fusion approaches leads to the production of catalytic energy conversion termed scalar energy. Thus, bio-disc is as well called scalar energy bio-disc [4]. In this study, the effect of bio-disc on crude oil properties and distillate yield was carried out on crude oils treated with the bio-disc. Experimental determination of SG, API gravity, viscosity, pour point and flash point were as well carried out on the treated and untreated samples to ascertain the impact of bio-disc on the measured properties. Furthermore, distillations of the treated and untreated crude samples were carried out and results then compared.

\section{Literature Review}

Insights on the literatures reviewed in the cause of this study are outlined below: [2] evaluated the crude oil physical as well as their chemical properties including their geologic importance. The study revealed that crude oils exhibit notable characteristics in terms of their chemical as well as physical properties which were seen to play significant roles in understanding the history of their geology and environmental origin. These properties when evaluated were found to serve as indices of correlation and could indicate the age of the geology and their alteration. Crude oil chemical properties differ in terms of pressure and geotemperatures plus katagenesis elements. [5] carried out a new retrofit optimization technique to revamp a crude oil distillation unit in Egypt. Based on the framework of optimization and the simulation that was rigorously conducted a new approach was developed to simultaneously address the challenges of the distillation column as well as the network of heat exchanger in order to maximize utilization the equipment already in existence. Several solutions from the retrofit optimization were obtained which were in the range of zero-modifications, additional areas simple exchangers to addition of equipment/units. The retrofit technique developed when deployed to crude distillation units will achieve its objectives which comprise reduction of atmospheric emissions, energy savings, enhancement of capacity, efficient raw materials utilization, changes in feedstock as well as improvement in profit. The new retrofit optimization on distillation operations saved $17 \%$ on every energy consumed and also on emissions. [6] evaluated the impact of the exposure of bio-disc on the water physico-chemical parameters obtained from three sources. Three sources of water were specifically 
energized with bio-disc which includes well, river and borehole waters. Dissolved oxygen, $\mathrm{pH}$, conductivity and temperature were the considered physico-chemical parameters. The non-energized water sample from the river had the highest $\mathrm{pH}$ value together with dissolved oxygen, with observance it was within the limit permissible, thus will not be a threat to both human as well as aquatic lives. [7] applied the technology of self-heat recuperation to the distillation of crude oil in order to reduce the energy requirements of crude distillation. Energy savings were achieved by developing compressors that worked at higher temperatures. [8] optimized heat-integrated systems for the distillation of crude oil. Simulation of both distillation process and as well as HEN was carried out in addition to building retrofit models for HEN into the overall framework of optimization. Optimization of the distillation process as well as the HEN at the same time were more attractive economically and practicable when compared with the optimization of the process of distillation and HEN individually. [9] analyzed the thermodynamics of the distillation systems of crude oil. The analysis of the thermodynamics of the distillation plants of crude oil was executed through the analysis of energy and exergy of the heaters mainly the VDU and the ADU. The profiles of pressure and temperature of ADU gave optimum efficiencies of energy, exergy efficiencies and rate of irreversibility at the conditions of operation. Change in the profile of pressure and temperature of VDU gave no meaningful change in the efficiencies both exergy and energy as well as the rate of irreversibility. Several literatures reviewed were not centred on the bio-disc effect on crude oil properties. Much of the works carried out with bio-disc on the literature were on water/wastewater and food products. In the area of comparison there are no literatures to compare with in terms of crude oil properties.

\subsection{Crude Oil and the Refining Process}

\subsubsection{Classifications of Crude Oil}

Categorization of crude oil depends on how much hydrocarbon components the crude oil contains. Crude oil could be Naphthene base, Paraffin base, [10] [11] asphalt base or mixed base. Mixed base has a mixture of all the categories which is dependent on the percentage composition of the hydrocarbon fractions it contains. When the aromatic content of crude oil is up to $80 \%$, the crude oil is regarded as aromatic base oil. When the distillate residue of crude oil is below $2 \%$ wax, the crude is termed asphaltic but when the distillate residue is above $5 \%$ wax, it is termed paraffinic [12]. Also, crude oil identity is categorized [13] depending on the value of $K_{w}$ (Watson Characterization factor) and CI (Correlation index). Mathematically, $K_{w}$ and $C I$ are computed from the equation [14]:

$$
\begin{gathered}
K_{w}=(T B)^{1 / 3} / G \\
C I=87552 / T B+(473.7) G-456.8
\end{gathered}
$$

where: $T B$-average boiling point, $\left({ }^{\circ} \mathrm{R}\right)$ and $S G$-specific gravity $60^{\circ} / 60^{\circ} \mathrm{F}$ is the specific gravity $60^{\circ} / 60^{\circ} \mathrm{F}$.

Crude oils that are highly paraffinic have $K_{w}$ values of the range $12.5-13.0$ 
while $K_{w}$ values of naphthenic oils are of the range $10.5-12.5$. The scale of the $C I$ are dependent upon the straight-chain. The $C I$ value of Paraffins is zero (0) while that of benzene is hundred (100). When the $C I$ value is lower, the paraffin hydrocarbon concentration will be more in the fraction and when the $C I$ value is higher the aromatics and naphthenes concentration will be higher [15]. Crudes that are paraffin based have low density which implies their API gravities are high and are the main gasoline constituents and therefore very much valued. They also produce lubricating oils in great amounts, less gasoline and kerosene as the refinery products in comparison with naphthene base crude oil [2]. Crude oil is also classified by the oil industry on the basis of geographic location the oil is produced (e.g., Brent, Oman or West Texas Intermediate), the API gravity of the crude oil as well as the sulfur content of the crude oil. When the density of crude oil is low, the crude is considered light crude and when the density is high the crude is considered heavy; the crude may also be termed sweet when little quantity of sulphur is contained in the crude oil and sour when substantial quantity of sulphur is contained in the crude oil [16].

\subsubsection{Crude Oil Refining}

The refining of crude oil involves changing the crude into different petroleum products which are utilized as fuels for heating, transportation, paving roads and also the generation of electricity. The products are also utilized as chemicals' making feedstock. During refining crude oil is broken down into different components and these are reconfigured in a selective manner into entirely new products [16]. Three fundamental steps are involved in crude oil refining process [16] [17], viz.: 1) Separation: The separation of crude oil into its various constituents is achieved by distillation. Modern technique of separation requires piping the crude oil through very hot furnaces. The liquids as well as vapors resulting from the separation are then discharged into the distillation units [16] [18]. These distillation units are ADUs found in all refineries and VDUs which are found in refineries that are more complex [9]. Inside DUs, the separation of liquids as well as vapors occur into components of petroleum termed fraction $s$ in order of the boiling points of the fractions. At the bottom are the heavy fractions while at the top are light fractions as shown in Figure 1. Fractions that are extremely light together with gasoline as well as LRG vaporize, and then rise to distillation tower top, where condensation back into liquids take place. Liquids that are medium in weights together with kerosene as well as distillates settle at the midpoint of distillation column. Liquids which are heavier in weight termed gas oils are separated at the lower part of distillation column, whereas fractions which are heaviest in weight which has the highest BT get settled at the column bottom [16]. 2) Conversion: At the end of distillation, the fractions which are heavy and with lower-value are further processed into higher-valued lighter products like gasoline. Here, the transformation of fractions from the units of distillation takes place into streams which finally are made finished products. The most generally utilized conversion technique is termed cracking because 


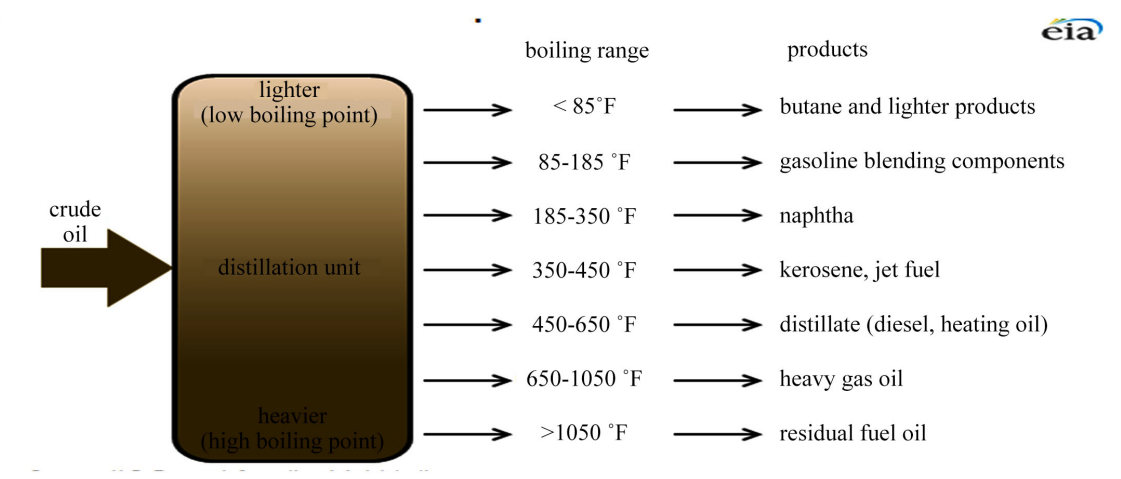

Figure 1. Crude oil DU and products [18].

pressure, heat, catalysts, and in some cases hydrogen is employed to crack heavy molecules of hydrocarbon into very light ones. Cracking unit usually has thick-walled, tall, reactors with rocket-shape and may be one or above one in number. It also has network of heat exchangers, furnaces and some other vessels. In Complex refineries, one or diverse crackers are incorporated with the inclusion FCCU and hydrocrackers/and hydrocracking units. Apart from cracking, other crude oil conversion techniques include alkylation which is reverse of cracking, occurs in skinny, tall columns and serially horizontal vessels with large size; and reforming which utilizes catalysts, moderate pressure and heat in turning of naphtha which is relatively a low-value and light fraction into gasoline components with high octane number [18]. 3) Treatment: Treatment involves the removal or significantly the reduction of molecules which are corrosive or could cause pollution of the air, mostly sulfur. The sulfur emission standards of European Union are highly stringent. Since 01/01/2009, diesel as well as gasoline sold within Europe is not permitted to contain above ten (10) ppm, or ten (10) mgpkg, of sulfur. These measures were intended for the improvement of air quality and also optimize the catalytic converters utilized in the treatment of exhaust gas. For diesel, sulfur removal termed desulfurization is carried out at temperature and pressure of $370^{\circ} \mathrm{C}$ and 60 bar respectively. The process utilized hydrogen in combination with sulfur forms $\mathrm{H}_{2} \mathrm{~S}$, which is thereafter treated for sulfur removal, an industrially utilized substance. Solution of $\mathrm{NaOH}$ (caustic soda or sodium hydroxide) is used to wash propane, butane and kerosene for the removal of thiols otherwise called mercaptans, a process termed sweetening [19].

\section{Materials and Method}

\subsection{Materials}

Bio-disc, crude oil, hydrometer, measuring cylinder (glass type), thermometer, ASTM SYD-510D cloud and pour point tester, test jar, cork, Pensky Martens flash point tester, Glass capillary viscometer, beaker, Stop watch, SYD 6536A Distillation tester, Distillation flask, burner, test tube, receiving cylinder.

\subsection{Method}

Laboratory tests were performed with crude oil samples treated and untreated 
with biodisc in line with API and ASTM standards.

\subsubsection{Preparation of Samples Crude Oil}

Five crude oil samples were collected from a reservoir in the Niger Delta with the samples designated as S11A, S12A, S13A, S14A and S15A. Crude samples S12A, S13A, S14A and S15A were treated with bio-disc by running over the oil on the bio-disc causing the crude to pick up scaler energy (resonance) that was emitted from bio-disc while sample $11 \mathrm{~A}$ was not treated with bio-disc. The treated crude samples were then transferred into labeled two (2) litres containers. To prevent interference, the crude samples were kept 5 meters from one another. Crude sample S11A that was not treated with bio-disc was the control samples and was kept in a different container. Sample S12A was treated twice, sample S13A was treated four times, sample S14A was treated six times and sample S15A was treated eight times. Figure 2 depicts the bio-disc while Figure 3 depicts treatment of crude oil with bio-disc.

\subsubsection{Determination of SG and API of Oil Samples Treated and Untreated Bio-Disc Treated}

The measuring cylinder and hydrometer were cleaned to remove any dirt present. Sample S11A was mixed in a closed container to reduce light components loss. Thereafter crude oil was poured into the measuring cylinder (glass type) till $500 \mathrm{mls}$ was reached. Hydrometer was then depressed into the crude oil contained in the cylinder by two-scale divisions and released, and made to float, with the hydrometer not touching cylinder sides. Sufficient time was allowed to ensure that the hydrometer gets to rest, thus enabling air bubbles' movement to the surface. Removal of air bubbles was made from hydrometer before readings were taking. Then, the crude oil specific gravity was read from the graduations on the hydrometer stem at the liquid surface. The experiment was then repeated for samples S12A, S13A, S14A and 15A respectively. The crude oil samples API gravity were computed as follows:

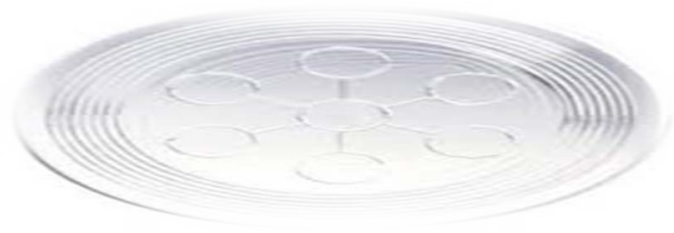

Figure 2. Bio-disc [4].

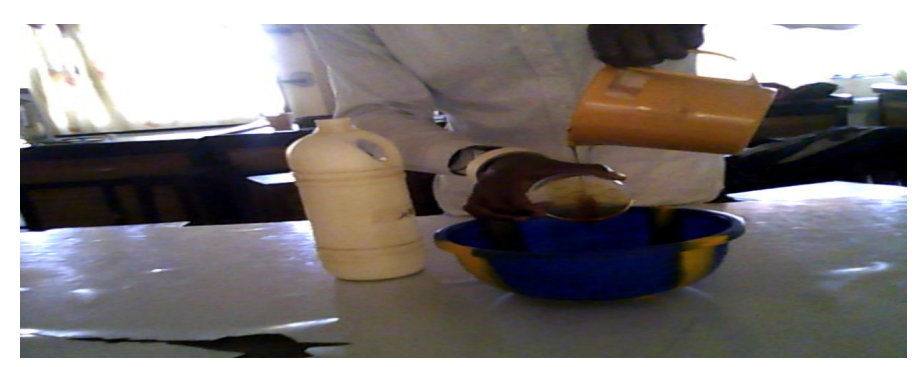

Figure 3. Treatment of crude oil with bio-disc. 


$$
{ }^{\circ} \mathrm{API}=\frac{141.5}{\text { Specific gravity at } 60^{\circ} \mathrm{F}}-131.5 \text {. }
$$

\subsubsection{Measurement of Pour Point of Crude Oil Samples}

The pour point tester was adequately and securely connected to power supply. Crude oil sample of $50 \mathrm{ml}$ was measured and transferred into the test jar and tightly closed with cork carrying thermometer. Crude oil sample in the test jar was loaded into the pour point tester jacket and then inserted into the tester unit refrigerated chamber. The tester was then powered and test jar monitored for every $1^{\circ} \mathrm{C}$ till freezing point of crude sample was reached. The temperature when there was no crude movement was read and recorded from the tester as pour point temperature with the test jar brought out and slanted horizontally for five (5) seconds.

\subsubsection{Flash Point of the Crude Oil Samples}

Flash point tester cup was cleaned and then dried. Sufficient quantity of crude sample was poured into the tester cup until it was filled to the mark. The cup was then inserted appropriately into the tester with thermometer placed in the tester. The tester heater with the stirrer was powered; and gas line opened with test flame powered. The stirrer was switched off after some time interval and sample flashed. Flashing continued for every $2^{\circ} \mathrm{C}$ temperature rise till a flash was noticed. The crude sample flash point temperature was read and recorded with the tester switched off.

\subsubsection{Determination of Crude Oil Samples Viscosity}

The crude sample viscosity was measured with glass capillary viscometer. The viscometer was first cleaned with Ethyl alcohol of $99.90 \%$ purity and allowed to dry. The viscometer was vertically held in temperature path which is controlled. Crude sample was carefully and gently introduced into the viscometer. By suction, fluid moves from higher bulb to lower bulb by means of capillary, and then viscosity measurement achieved by taken the time it took it for the crude oil sample to move through the viscometer tube. The time it took the crude sample to move between the upper and lower bulbs is proportionally equal to viscosity and the time was measured with the aid of stopwatch. The viscosity measurements were taken at room temperature. The kinematic viscosity obtained was converted to dynamic viscosity through the equation:

$$
\mu=v \rho .
$$

\subsubsection{Distillation of Crude Oil Samples}

The Distillation tester was set-up and connected to power source. Measurement of crude oil sample of $100 \mathrm{mls}$ in which oil to be distilled was carried out with the aid of measuring cylinder. The $100 \mathrm{mls}$ measured crude sample was transferred into distillation flask, thereafter placed into distillation tester heater and the equipment switched on. Placement of receiving cylinder at the delivery seg- 
ment of the tester was made for distillate collection from crude sample with stopwatch utilized to record each distillate recovery time. The recovered distillate was then transferred into test tube for measurement and recording of each distillate volume. Figure 4 depicts the distillation tester.

Observations

- Liberation of crude sample dissolved gases occurred at temperature below $40^{\circ} \mathrm{C}$.

- At $93^{\circ} \mathrm{C}-177^{\circ} \mathrm{C}$ temperature range, gasoline fraction got distilled out of crude oil samples.

- At $177^{\circ} \mathrm{C}$ to $293^{\circ} \mathrm{C}$ temperature range, kerosene fraction got distilled out of crude oil samples.

- At $293^{\circ} \mathrm{C}$ to $343^{\circ} \mathrm{C}$ temperature range, diesel fraction got distilled out of crude oil samples.

\section{Results and Discussion}

\subsection{SG and API}

SG provides an indication of high molecular as well as light weight HC presence in a crude oil. The lower the SG value, the greater the HC amount in the crude oil [20] [21]. From Table 1, sample S11A which was not treated had SG of 0.868 and ${ }^{\circ}$ API of 31.52 while samples S12A, S13A, S14A and S15A had a reduced SG and an increased ${ }^{\circ} \mathrm{API}$. From the table, it is evident that as the number of times the crude oil sample treatment with bio-disc increases, the sample specific gravity decreases thereby leading to increase in API gravity of the crude oil. The implication of the result is that, sample S15A more HC content than all the treated samples and sample S11A has the lowest. Thus, treating the crude oil sample with bio-disc influences the API gravity of the crude samples thereby increasing the crude oil worth. Crude oil price is normally dependent on the crude's API gravity and oils whose API gravity is high command higher prices while those with lower API command lower prices. This is because more quantities of light products will be produced from oil with high API when refined in comparison with oil whose API is low; and also the technical problems that are associated with oil with high API is low with the problems as asphaltenes, sulpur content, metals etc. in crude oil.

Table 1. SG and API of samples crude oil.

\begin{tabular}{cccc}
\hline Crude oil samples & SG & •API & No of treatments with Biodisc \\
\hline S11A & 0.868 & 31.52 & 0 \\
S12A & 0.862 & 32.65 & 2 \\
S13A & 0.860 & 33.03 & 4 \\
S14A & 0.856 & 33.80 & 6 \\
S15A & 0.850 & 34.97 & 8 \\
\hline
\end{tabular}




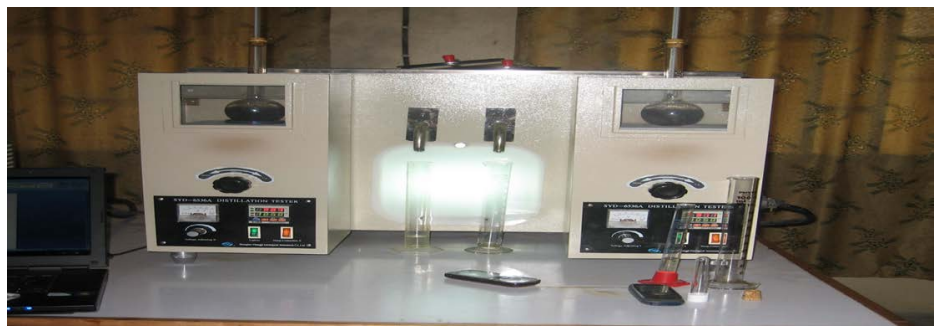

Figure 4. Distillation tester.

\subsection{Pour Point}

Pour point is a property utilized for measurement of the crude oil's wax content. From Figure 5, the pour point ranges from $-14.5^{\circ} \mathrm{C}$ to $-15.5^{\circ} \mathrm{C}$ while paraffinic crudes have a pour point of $-12^{\circ} \mathrm{C}$ to $-15^{\circ} \mathrm{C}$ and naphthenic crudes a pour point of $-30^{\circ} \mathrm{C}$ to $-50^{\circ} \mathrm{C}$. From the results, it is evident that these crude samples are among the paraffinic oils and values more than $15^{\circ} \mathrm{C}$ is an indication that the crude was high in wax content. Also from Figure 5, the pour point of the sample $\mathrm{S} 11 \mathrm{~A}$ which was not treated was $-14.5^{\circ} \mathrm{C}$ while those which were treated decreased. From the figure, it's evident that as the number of times the crude oil samples were treated with bio-disc increases, the crude samples' pour point decreases. Thus, treatment of the crude samples with the bio-disc tends to turn the crudes to naphthenic crudes by further reducing the pour point of the crude samples.

\subsection{Viscosity of Crude Samples}

Figure 6 shows decrease in viscosity of the crude samples as the number of times the samples were treated with the bio-disc increases. Sample S11A had the highest viscosity of $2.59 \mathrm{cp}$ while treated samples had lower viscosities. Sample S12A that was treated twice had a reduced viscosity of $2.36 \mathrm{cp}$ after treatment as against $2.59 \mathrm{cp}$ obtained for sample S11A. The low viscosity values of the treated samples are an indication that the crude sample which originally had high viscosity with high molecular weight HCs was made to have low molecular weight HCs as a result of treatment with bio-disc. This indicates there was a tremendous alteration of the crude samples viscosity resulting from crude treatment with bio-disc thereby increasing the crude samples' mobility.

\subsection{Flash Point}

Flash point is the temperature measurement at which sufficient vapour exists above sample of a liquid capable of causing gnition. Significantly, it is a product applications feature commonly utilized for safety specification. Flash points reflect crude oil's boiling point. From Figure 7, sample S11A had the lowest flash point of $65^{\circ} \mathrm{C}$ while those of S12A - S15A increased. Also from Figure 7, the crude samples' flashpoint increases as the number of times the crude samples were treated with bio-disc increases. Thus, treating crude samples with bio-disc causes much significant increase in the crude's flash point thereby reducing the 
flammability of the crude oil. Therefore crude oils with high flash point are less volatile and can be easily stored and transported.

\subsection{Distillate Yield of Samples of Crude Oil}

After the determination of the crude samples' physical properties, distillation tester was utilized to distil the oil samples. Table 2 depicts the distillate yields of the oil samples basically comprising gasoline, kerosene and diesel which increased as the number of times the crude samples was treated with bio-disc increased. Sample S11A which was not treated had the lowest distillate yield which is $9.6 \mathrm{mls}$ for gasoline, $12.2 \mathrm{mls}$ for kerosene and $14.2 \mathrm{mls}$ for diesel which increased for treated samples (S12A, S13A, S14A and S15A) with sample S15A having the highest distillate yield of $14.4 \mathrm{mls}$ for gasoline, $17.0 \mathrm{mls}$ for kerosene and $19.8 \mathrm{mls}$ for diesel. This increased distillate yield was attributed to alteration of crude oil properties due to sample treatment with bio-disc.

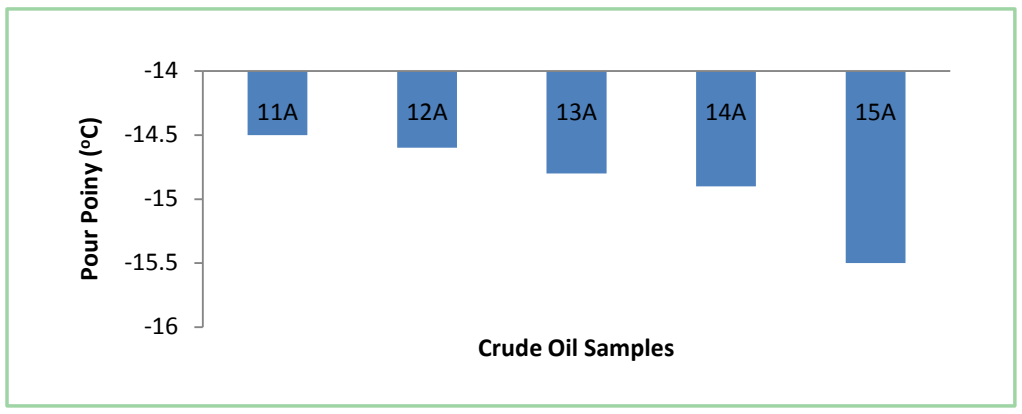

Figure 5. Pourpoint of crude samples.

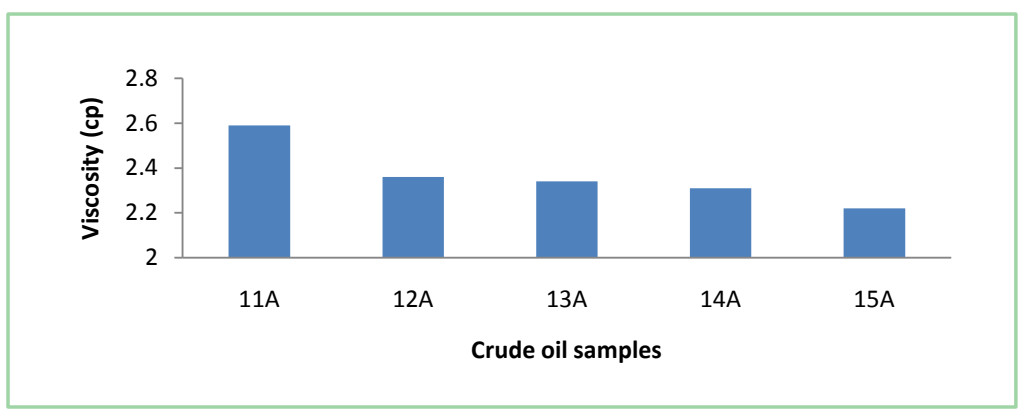

Figure 6. Viscosity of each crude oil sample.

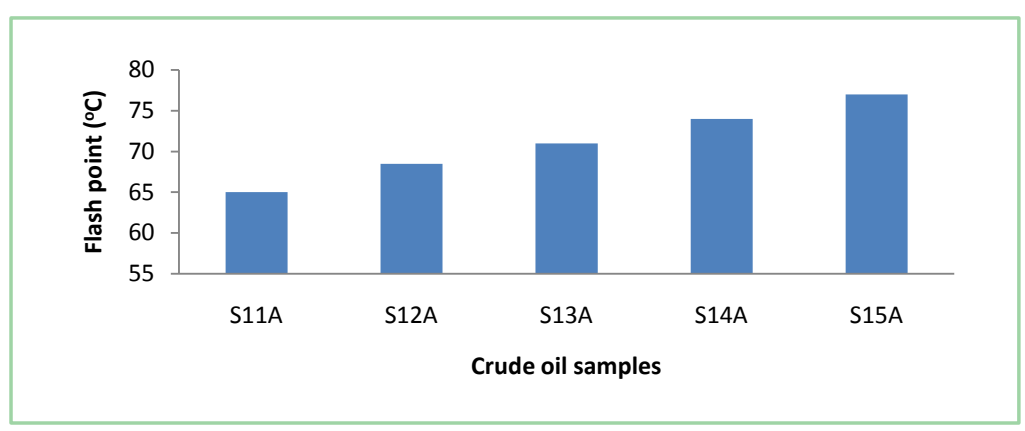

Figure 7. Flash points of crude oil samples. 
Table 2. Distillation output result of the crude oil samples.

\begin{tabular}{ccccccc}
\hline Distillation Parameters & \multicolumn{5}{c}{ Sample 11ASample 12ASample 13A Sample 14A Sample 15A } \\
\hline Vol of Gasoline Recovered (Mls) & 9.6 & 10.6 & 12.2 & 13.4 & 14.4 \\
Time of Gasoline Recovered (Mins) & $7: 18$ & $8: 10$ & $9: 14$ & $11: 17$ & $14: 07$ \\
Gasoline Recovery Temp ( $\left.{ }^{\circ} \mathrm{C}\right)$ & $93-177$ & $93-177$ & $93-177$ & $93-177$ & $93-177$ \\
Vol of Kerosene Recovered (Mls) & 12.2 & 13.6 & 14.4 & 15.2 & 17.0 \\
Time of Kerosene Recovered (Mins) & $18: 26$ & $30: 23$ & $38: 05$ & $49: 32$ & $64: 12$ \\
Kerosene Recovery Temp ( $\left.{ }^{\circ} \mathrm{C}\right)$ & $177-293$ & $177-293$ & $177-293$ & $177-293$ & $177-293$ \\
Vol of Diesel Recovered (Mls) & 14.2 & 15.3 & 16.3 & 17.9 & 19.8 \\
Time of Diesel Recovered (Mins) & $69: 34$ & $87: 45$ & $95: 60$ & $104: 35$ & $113: 07$ \\
Diesel Recovery Temp ( $\left.{ }^{\circ} \mathrm{C}\right)$ & $293-343$ & $293-343$ & $293-343$ & $293-343$ & $293-343$ \\
\hline
\end{tabular}

\section{Conclusions}

The results of the laboratory experiments conducted in this study show that treating crude oil with bio-disc has profound effect on the physical properties and the distillate yield of the samples of crude oil treated with it. Treatment of oil samples with bio-disc altered the behaviourial characteristics of the crude oil treated with it. From the study these conclusions are drawn:

- The specific gravity of the crude oil samples decreases as the number of times the samples were treated with bio-disc increases. This increased the API of the crude samples thereby increasing the oil samples' worth due to treatment of the samples with bio-disc.

- The pourpoint of the crude samples decreases with increase in number of treatments of crude samples with bio-disc. This tends to turn the samples from paraffinic crude oil to naphthenic crude.

- The crude samples viscosity decreases with increase in number of treatments of crude samples with bio-disc. The decrease in crude samples viscosity due to their treatment with the bio-disc increases the oil samples mobility.

- The flash point of the samples increased with increase in number of treatments of crude samples with bio-disc. This in turn reduces the crude samples volatility and flammability making the oils storable and transportable without challenges.

- The distillate yield of the oil samples mainly gasoline, kerosene and diesel increased with increase in number of treatments of crude samples with bio-disc.

\section{Acknowledgements}

The authors appreciate the support of DPR and SPDC for the assistance rendered in ensuring that the crude samples were provided for the experiments.

\section{Conflicts of Interest}

The authors declare no conflicts of interest regarding the publication of this paper. 


\section{References}

[1] Petroleum Wikipedia (2008). http://en.wikipedia.org/wiki/petroleum

[2] Madu, A.J. and Ugwu, R.E. (2015) Physical and Chemical Properties of Crude Oils and Their Geologic Significance. International Journal of Science and Research, 6, 1514-1521.

[3] Gatlin, C. (1960) Petroleum Engineering Drilling and Well Completions. Prentice-Hall Inc., Englewood Cliffs.

[4] Amezcua (2014). https://www.nairaland.com/208012/bio-disc-living-water-scalar

[5] Mamdouh, G., Dina, K., Fatma, A. and Hemdan, N.E. (2013) A New Optimisation Based Retrofit Approach for Revamping an Egyptian Crude Oil Distillation Unit. Energy Procedia, 36, 454-464. https://doi.org/10.1016/j.egypro.2013.07.051

[6] Obaroh, I.O., Haruna, M.A., Muhhammed, A. and Akanji, A. (2016) Effect of Bidisc Exposure on Some Physicochemical Parameters of Water from Three Different Sources. European Journal of Pure and Applied Chemistry, 3, 58-65.

[7] Kansha, Y., Akira, K. and Atsushi, T. (2009) Application of the Self-Heat Recuperation Technology to Crude Oil Distillation. Collaborative Research Centre for Energy Engineering, Institute of Industrial Science, University of Tokyo, Tokyo.

[8] Lluvia, M.O. and Megan, J. (2015) Optimization of Heat-Integrated Crude Oil Distillation Systems. Part III: Optimization Framework. Industrial and Engineering Chemistry Research, 54, 5018-5036. https://doi.org/10.1021/ie503805s

[9] Husain, A. and Ibrahim, D. (2005) Thermodynamic Analysis of Crude Oil Distillation Systems. International Journal of Energy Research, 29, 637-655. https://doi.org/10.1002/er.1097

[10] Al-Dahhan, W. (2016) Evaluation and Comparison between Crude Oil Straight Run Fractions and Its Commercial Fractions at Dura Oil Refinery. Journal of Al-Nahrain University, 19, 18-27. https://doi.org/10.22401/JNUS.19.3.03

[11] Al-Dahhan, W.H. and Mahmood, S.M. (2019) Classification of Crude Oils and Its Fractions on the Basis of Paraffinic, Naphthenic and Aromatics. Al-Nahrain Journal of Science, 22, 35-42. https://doi.org/10.22401/ANJS.22.3.05

[12] Petroleum and Petroleum Products (2020). https://www.uotechnology.edu.iq/dep-chem-eng/second\%20year/Fuels\%20Technol ogy\%20Dr.\%20Intisar/lect2.pdf

[13] Chang, A.F. (2012) Refinery Engineering Integrated Process Modeling and Optimization. Wiley, Hoboken. https://doi.org/10.1002/9783527666836

[14] Riazi, M. (2005) Characterization and Properties of Petroleum Fractions. ASTM International, West Conshohocken. https://doi.org/10.1520/MNL50_1ST-EB

[15] Glean, E. and James, H. (2012) Petrochemical Refining Technology and Economics. Fifth Edition, CRC Press, Boca Raton.

[16] US EIA (2017) Petroleum. https://www.eia.gov/kids/energy-sources/oil

[17] Meyers, R.A. (2003) Handbook of Petroleum Refining Processes. 3rd Edition, McGraw-Hills Publishers, New York.

[18] US EIA (2012) Crude Oil Distillation and the Definition of Refinery Capacity-Today in Energy. https://www.eia.gov/todayinenergy/detail.php?id=6970

[19] Plante Energies (2020) The Three Stages of Refining. https://www.planete-energies.com/en/medias/close/three-stages-refining

[20] Onojake, M.C., Osuji, L.C. and Oforka, N.C. (2013) Preliminary Hydrocarbon Analysis of Crude Oils from Umutu/Bomu Fields, Southwest Niger Delta, Nigeria. 
Egyptian Journal of Petroleum, 22, 217-224.

https://doi.org/10.1016/j.ejpe.2013.06.001

[21] Connan, J. (1980) Biological Markers in Crude Oils. In: Petroleum Geology in China, 4th Edition, Pennwell, Tulsa, 48-70. 


\section{Nomenclature}

API-American Petroleum Institute

SG-Specific Gravity

ASTM-American Society for Testing and Materials

${ }^{\circ} \mathrm{C}$-Degree Centigrade

${ }^{\circ} \mathrm{F}$-Degree Fahrenheit

ML-Millilitre

BT-Boiling Point

$\mathrm{MMB} / \mathrm{D}-$ Million Barrels/Day

HEN-Heat Exchanger Network

VDU-Vacuum Distillation Unit

ADU-Atmospheric Distillation Unit

DU-Distillation Unit

$\%$-Percentage

DPK-Dual Purpose Kerosene

PMS-Premium motor spirit

US. EIA-United States Energy Information and Administration

LRG-Liquefied Refinery Gas

FCCU_Fluid Catalytic Cracking Unit

Ppm-Parts per Million

MgpKg-Milligrams per Kilogram

$\mathrm{H}_{2} \mathrm{~S}-$ Hydrogen Sulfide

$\mathrm{HC}$-Hydrocarbon

WRT-With Respect to

DPR-Department of Petroleum Resources

SPDC-Shell Petroleum Development Company 